\title{
Prevalence and Profile of Migraine Patients in Brazzaville, Congo
}

\author{
Ossou-Nguiet Paul Macaire ${ }^{1,2, *}$, Mpandzou Ghislain Armel ${ }^{1,2}$, Ongoly Ikora Héloïse Stéphanie ${ }^{2}$, \\ Diatewa Josué Euberma ${ }^{1,2}$, Obondzo Aloba Karen Lise Charmel ${ }^{2}$, \\ Motoula Latou Dinah Happhia ${ }^{1,2}$
}

${ }^{1}$ Department of Medicine, Faculty of Health Sciences, Marien Ngouabi University of Brazzaville, Brazzaville, Congo

${ }^{2}$ Department of Neurology, University Hospital of Brazzaville, Brazzaville, Congo

\author{
Email address: \\ ossoupm@gmail.com (Ossou-Nguiet P. M.) \\ ${ }^{*}$ Corresponding author
}

\section{To cite this article:}

Ossou-Nguiet Paul Macaire, Mpandzou Ghislain Armel, Ongoly Ikora Héloïse Stéphanie, Diatewa Josué Euberma, Obondzo Aloba Karen Lise Charmel, Motoula Latou Dinah Happhia. Prevalence and Profile of Migraine Patients in Brazzaville, Congo. American Journal of Psychiatry and Neuroscience. Vol. 7, No. 1, 2019, pp. 24-29. doi: 10.11648/j.ajpn.20190701.15

Received: March 14, 2019; Accepted: April 27, 2019; Published: June 18, 2019

\begin{abstract}
Migraine is a chronic disease evolving through recurrent seizures; it constitutes a frequent reason of consultation in neurology. Epidemiological data on migraine in the world are available, but no study has been conducted in general population in Congo. To determinate the prevalence of migraine in population of Brazzaville, we conducted a prospective cross-sectional, door-to-door study. This study took place from March $1^{\text {st }}$ to July $31^{\text {st }}$, 2018 , in the city of Brazzaville. Regarding all subjects over 18 years old, living in Brazzaville for over ten years. The statistical analysis was performed using SPSS 20.0 software for Mac. The prevalence of migraine was 11,3\% in Brazzaville, with 6\% definite migraine and 5,3\% of probable migraine. Women are more affected than men respectively $63,5 \%$ and $36,5 \%$. Migraine without aura is more common than migraine with aura. Migraine is a public health problem because of its prevalence. Its affects the young adult and more preferably the woman The knowledge of the epidemiology of migraine in Brazzaville will lead to better awareness-raising actions.
\end{abstract}

Keywords: Migraine, Prevalence, Brazzaville

\section{Introduction}

Migraine is a common reason for consultation in neurology. It is one of the most disabling primary headaches [1]. It corresponds to a chronic neurological disorder characterized by recurrent painful crises, associated with multiple neurological symptoms [2]. Migraine mainly affects people aged 35 to 45 ; The first attacks generally appear at puberty and a clear decrease in symptoms is observed after 50 years [3]. It can manifest itself with or without aura. The aura corresponds to a focal and transient neurological dysfunction that precedes or accompanies the headache [4]. It is estimated that in $40-50 \%$ of cases, migraine sufferers present two or more seizures per month [5]. The diagnosis of migraine is essentially clinical. A major breakthrough in the study of headaches was the publication in 1988 of the headache diagnosis criteria of the International Headache Society (IHS), updated in 2004 and more recently in 2013 and $2018[1,6]$. This classification remains to this day an essential tool for neurologists and practitioners in the management of headaches and migraine. It has made it possible to carry out numerous studies both in hospitals and in the general population. Several epidemiological studies have been conducted in Western countries and in Africa. In 2009 , the global prevalence of migraine was estimated at $11.6 \%$ [7]. It would be 8 to $10.4 \%$ in Africa, $10.1 \%$ in Asia, $11.4 \%$ in Europe, $9.7 \%$ in North America and 16.4\% in South and Central America [8]. Women are more frequently affected than men because of a hormonal influence; with a sex ratio of two women for one man [3, 4]. In Western countries, the prevalence of migraine has been estimated at $18.2 \%$ in women and $6.5 \%$ in men [1].In the Congo and more 
specifically in Brazzaville, the prevalence of migraine in the general population has not been studied to date. The few studies carried out on headaches have been done in neurology consultation [9], which justifies the interest for the realization of this study in general population. The goal is to determine the prevalence of migraine and the profile of migraine patients.

\section{Patients and Method}

It was a cross-sectional, door-to-door study conducted between March 1st and July 31st, 2018. This study was conducted in Brazzaville, the political and administrative capital of the Republic of Congo. It has an area of about 11500 hectares [10], counts districts for a population estimated at 1,838,348 inhabitants [11].

Have been included, all subjects of at least 18 years, living in Brazzaville and having clearly expressed their consent. Not included were all subjects with a considerable cognitive or physical disability that did not allow them to answer the questionnaire and those from another locality who had been living in Brazzaville for less than ten years. We excluded all subjects who partially answered the questionnaire. The estimated sample size of 864 subjects was calculated by the Schwartz formula, with a margin of error of $2 \%$. For each borough we proceeded to a weighting from the population of each district. Subjects were selected by random cluster sampling. The drawing of lots concerned the boroughs, neighborhoods, alleys, plots and households. The field survey was conducted by students in the final year of medical school who were trained prior to the various headache classifications. For all cases of migraines, the diagnostic confirmation was made, according to the criteria of ICHD 3, by 2 neurologists participating in the study. The investigators went door-to-door in all the districts of Brazzaville for filling in the questionnaire. Certain migraine was retained when all criteria A, B, C, D and E of migraine with or without aura were filled. Probable migraine patients were those who met all but one of the diagnostic criteria and did not meet the criteria for another type of headache.

The study variables were socio-demographic, clinical and therapeutic.

Statistical analysis was performed with SPSS 22.0 for Mac software. The numbers were compared by Pearson's Chi- 2 test or Fisher's test, and averaged by the Student's t-test or the Whitney-Mann test according to the normality of the distribution.

Ethical considerations were respected: The study was done anonymously. The subjects of the survey were interviewed individually. The information collected is confidential, coded and identified by a number. Informed consent was obtained for each subject interviewed.

\section{Results}

During the study 1048 subjects were selected for interview, of which 31 (3\%) refused to continue the interview. A total of 1017 subjects were interviewed, representing a participation rate of
97\%. Among the subjects interviewed, there were 288 (28.3\%) with history of recurrent headache. According to the IHS diagnostic criteria, a migraine was diagnosed in 115 (39.9\%) of the 288 headache subjects.

The prevalence of migraine was estimated at $11.3 \%$ in the total population studied, (11,300 per 100,000 inhabitants).

According to the diagnostic rigor of the IHS classification, there were $61(53.0 \%)$ certain migraines and $54(27.0 \%)$ probable migraines.

Figure 1 describes the prevalence of migraine in each district.

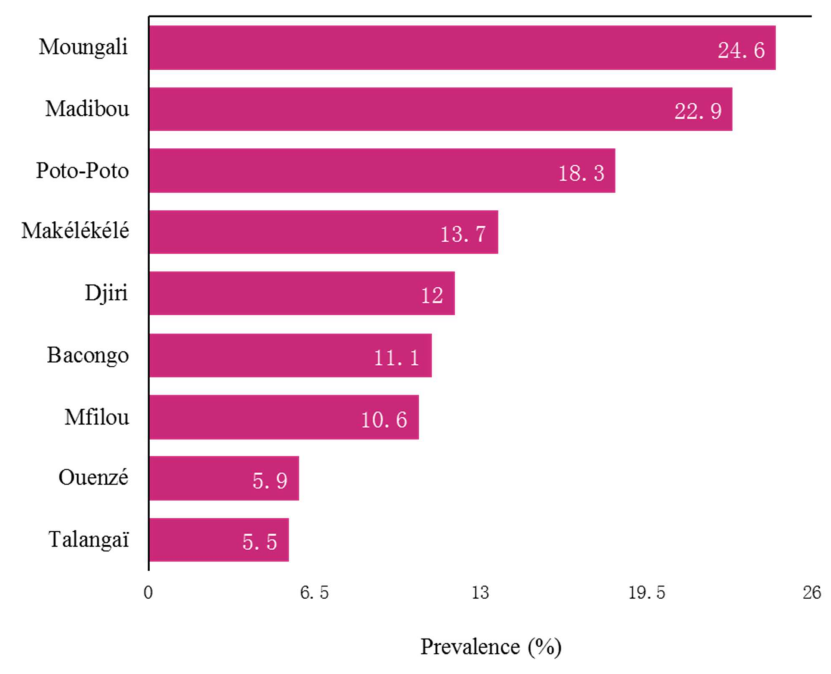

Figure 1. Prevalence of migraine in each district.

The mean age of migraine subjects was $34.3 \pm 11.7$ years [18 - 63 years]. The sex ratio was 0.57 , or $42(36.5 \%)$ men and $73(63.5 \%)$ women, with a significant difference $(\mathrm{p}=$ $0.024)$.

Regarding employment status, informal sector workers are the most represented as well as single persons and those with secondary education (Table 1).

Table 1. Sociodemographic characteristics of migraine sufferers.

\begin{tabular}{lll}
\hline Caracteristics & $\mathbf{n}$ & $\mathbf{\%}$ \\
\hline Professional status & & \\
officials & 13 & 11,3 \\
Privatesector agents & 18 & 15,7 \\
Informal Sector Agent & 37 & 32,2 \\
Students / Students & 31 & 27,0 \\
Unemployed & 14 & 12,2 \\
Retirement & 02 & 01,7 \\
Marital status & & \\
Married & 09 & 07,8 \\
Single & 66 & 57,4 \\
Living in a relationship & 38 & 33,0 \\
Widowed & 02 & 01,7 \\
Divorced & 00 & 00,0 \\
Level of instruction & & \\
Primary & 09 & 07,8 \\
Secondary & 59 & 51,3 \\
Superior & 45 & 39,1 \\
Unschooled & 02 & 01,7 \\
Property of housing & & \\
Owner & 54 & 47,0 \\
Leaseholder & 61 & 53,0 \\
\hline
\end{tabular}


With regard to professional activity, the average working time and overtime were respectively $8.2 \pm 2.7$ [ 3 to 20$]$ and $2 \pm 0.7$ [0.5 to 3$]$.

In the migraine population, 70 subjects $(60.9 \%)$ reported having a parent with headache.

One hundred and four (90.4\%) migraine patients specified the age of onset as well as seniority. The mean age of onset of migraine was $26.1 \pm 10.3$ years [12 to 44 years], with a median age of 6.1 years with an interquartile range between 3.3 and 10.9 years. As for the number of seizures, $100(87 \%)$ subjects had at least five seizures responding to the IHS criteria for migraine.

Forty-nine (42.6\%) subjects reported having an aura. The different types of aura are shown in Figure 2. Triggering factors are shown in Figure 3.

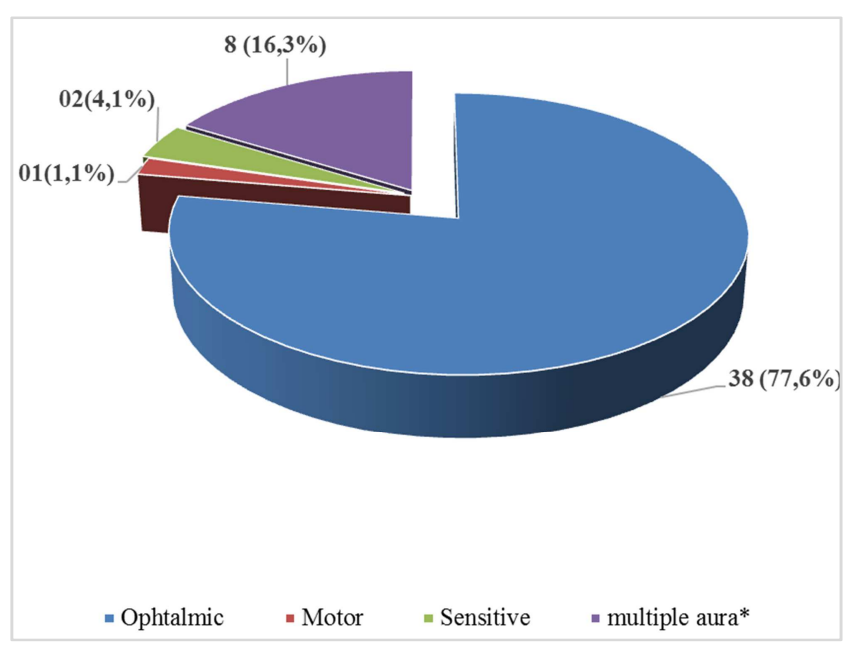

* Multiple aura is the association of two or more types of aura.

Figure 2. Type of aura.

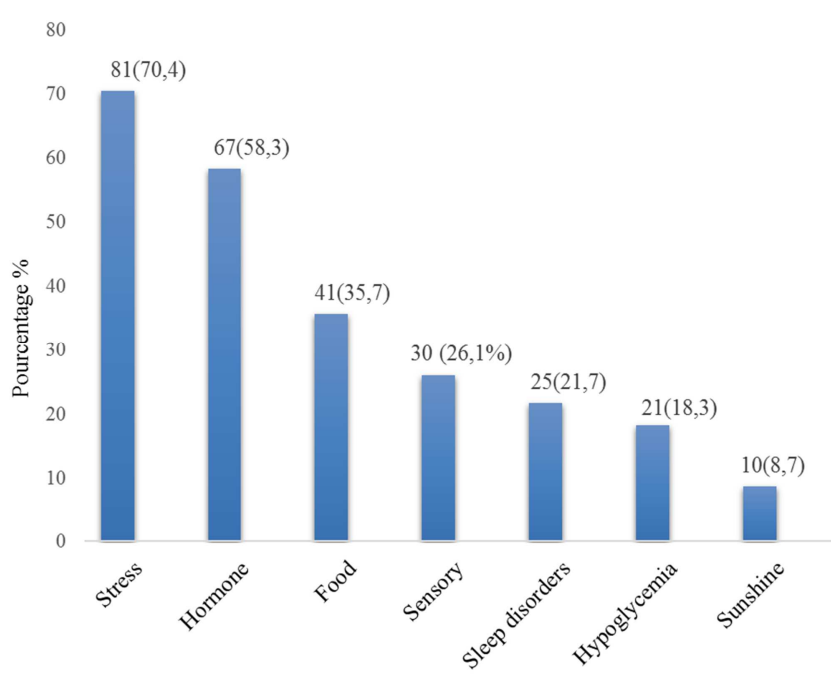

Figure 3. Triggering factors of migraine.

\section{Discussion}

The prevalence of migraine found in our study at $11.3 \%$ (or 11300 per 1000 inhabitants) is superposable to data from the literature because the prevalence of migraine was estimated in 2016 , at $11.6 \%$ in the world and $10,4 \%$ in Africa $[1,12]$. In 2018, in the absence of field study data, the GBD using Bayesianmeta-regression estimated the prevalence of migraine in Congo between 11,000-12,000 [13].

In Egypt, the prevalence of migraine in 2015 was $17.3 \%$, in a study conducted in rural and urban areas with the diagnostic criteria of those of ICHD IIIb [14]. The diagnosis of migraine had been validated by two neurologists. Using a methodology similar to ours, this higher prevalence could be related to the combination of prevalence in urban and rural areas. Some authors report differences in prevalence between rural and urban areas $[15,16]$.

In Zambia, a prevalence of migraine of $21.7 \%$ was found in rural areas and $23.7 \%$ in urban areas [15]. In this study the diagnosis of migraine was mainly made by science students and staff of the epileptic care center of Chikankata. For the reassessment of the diagnosis made in the field, a sub-sample of subjects was re-examined for consultation. In rural areas the subjects were re-interviewed by a general practitioner; in urban areas by a psychiatrist. Only those who experienced a recent worsening of headache frequency and / or intensity presented for the reassessment of the diagnosis, suggesting a self-selection bias motivated by the need for medical care. Thus, a considerable difference was observed between the sub-sample and the main sample, with a diagnostic sensitivity for migraine of $48 \%$ with a specificity of $57.1 \%$ and a weak agreement of the two diagnostic phases, determined by the Kappa coefficient of 5.14. \% for the diagnosis of migraine. No neurologist participated in the two diagnostic phases, suggesting a possible overestimation of the "positive" diagnosis. Also their selection criteria included even subjects with day headaches, excluded in our study.

In Ethiopia, a study conducted in conditions similar to that of Zambia, found a prevalence of migraine of $19.0 \%$ in the entire population (rural and urban). However, the diagnosis of migraine was determined by an algorithm based on ICHD2 criteria [17]. In these two studies, apart from the problem relating to the criteria for selecting subjects, there is also a problem of validation of the diagnosis of migraine. Most other African data come from studies of more specific populations; school children, workers, etc. [18-20].

In Asia, even higher prevalences have been reported; in Nepal 34.1\%, in India 25.6\%, in Bangkok 29.1\% [16, 21, 22]. With regard to Nepal, although it is a poor country, no association between migraine and low socioeconomic level has been found. The authors explain their high prevalence by high altitude. Living above 1000 meters would increase the risk of migraines by $60 \%$ [21]. In India, the high prevalence would be explained by methodological differences [16], whereas that of Thailand would be explained only by the low socio-economic level [22].

In Europe, high prevalence of migraine have also been reported, including 25.8\% in Belgium, $20.3 \%$ in Russia and $17.0 \%$ in France [23-25]. According to the GBD Headache Collaborators 2018 the prevalence of migraine in these European countries is above $16 \%$ [13]. In the United States 
prevalences are close to ours and estimated between 14 and $15 \%[13,26]$.

In summary, the prevalence of migraine varies from country to country and is influenced by methodological differences (study population, sampling technique, interview methods, diagnostic criteria, diagnostic validation). but also cultural, environmental and individual differences as well as factors associated with migraine [27]. However, this prevalence varies on average between 8 and $21 \%$ according to the GBD Headache Collaborators 2018 [13].

Migraine without aura is usually more common than aura with aura. In our study, a similar finding was observed, with $57.4 \%$ of migraine without aura and $42.6 \%$ with aura. These results corroborate data from the literature that report a rarity of migraine with aura $[4,25]$. The visual aura is the type of aura most found in our study $(40 \%)$. Streel et al [25] in Belgium found a frequency of $40.8 \%$. Our results corroborate the data in the literature [18, 28, 29].

Based on the classification of ICHD IIIb, among migraine patients, we found $53.0 \%$ of certain migraines and $27.0 \%$ of probable migraines. According to the study population, the prevalence of certain migraine was $6.0 \%$ and that of probable migraine was $5.3 \%$. In the various studies conducted, certain migraine is more frequent than probable [26, 28]. In Zambia, certain migraine accounted for $12.7 \%$ and the probable $10.6 \%[15]$.

Regarding the geographical situation, especially the district, the highest prevalences were found in Moungali and Madibou. Indeed, Moungali is a district dominated by commercial activities, three large markets and many bars and discotheques sources of noise pollution. This may explain this high prevalence, especially since most of the subjects in our study reported having a migraine triggered by sensory factors and more particularly noise. Solotareff et al [30] in France reported that noise pollution was a factor triggering seizures in $32.4 \%$ of cases in migraine children. The high prevalence of Madibou could be explained by its geographical location. Indeed, it is one of the last two boroughs added to Brazzaville in 2011, straddling the urban and rural areas. Some report a higher prevalence in urban areas that is related to the disparity between lifestyle stress levels [8]. The differences in prevalence between urban and rural areas are reported in the literature $[8,15,16]$.

A female predominance of migraine was found in our study. Some cohort studies estimate that in a lifetime, the prevalence of migraine in women is between 33 and $43 \%$ while it is $18 \%$ in men with a statistically significant difference $[25,31]$. These results agree with those reported in the literature, where migraine is designated as a predominantly female pathology $[4,8,14,15]$. Sex hormones, including estrogen, seem to have an important place in the pathophysiology of migraine. This implication is highlighted, on the one hand, by the epidemiology of migraine itself with a peak of incidence during the female reproductive life, on the other hand, by the maximum incidence of migraine attack in women, in the per menstrual period, when estrogen and progesterone levels drop rapidly following luteolysis. Estrogen changes are thought to be involved in the modulation of neuronal excitability, cerebrovascular activity, pain sensitivity, and neuroendocrine axes during the menstrual cycle [32, 33]. Similarly, it is accepted that in children migraine is more common in boys and the tendency is reversed after puberty due to the action of hormones [34].

The mean age of onset of migraine in our subjects was $26.1 \pm 10.3$ years, with a median age of 6.1 years. Migraine is indeed the prerogative of the young adult, especially second and third decade with a peak prevalence between 30 and 39 years $[35,36]$. In women, the prevalence peak is bimodal: at $25 \pm 8.6$ and $50 \pm 15.8$ years $[13,37]$.

Migraine, like other primary headaches, affects all socioprofessional classes $[20,23,38]$. In our study, migraine affects all occupations but with a predominance for informal sector workers (32.2\%) and students / students (31.7\%). According to the socio-economic level, subjects with an average socio-economic level (58.3\%) and high (33.0\%) are the most affected; while extremes: high socioeconomic levels $(0.9 \%)$ and low $(7.8 \%)$ are less so. The studies concerning the relationship between socioeconomic status and migraine are controversial [16, 21, 24, 25]. However, an important correlation between migraine and socioeconomic level has been found in most of these studies [16, 26, 28].

Studies of student populations have found a prevalence of $11.3 \%$ in Cotonou and 14.2\% in Parakou in Benin and 17.3\% in Mali $[20,38,39]$. In our study, it was $11 \%$, with 31 students and / or students, results that are similar to those of the above studies. In Cotonou the prevalence of migraine in a working population was $8.9 \%$ [18], in our study it is $13.0 \%$. This difference is explained by the fact that this study focused on a specific population with a higher risk of migraine. Indeed, the literature data report a high prevalence of migraine among workers. Our labor force (522) was significantly lower than theirs (938). In addition, the diagnostic criteria used in this study were those of the 1988 IHS, criteria in which the notion of probable migraine was not taken into account. An epidemiological study conducted in France showed that intermediate socio-occupational categories seemed to be more affected by migraine than intellectuals and senior managers [40].

The levels of education most affected in our study were the secondary and the higher level. Studies report that migraine is more common in high-educated individuals [28, 38]. Maiga et al [19] in Mali, have established a causal link between school activity and the exacerbation of crises; noting a marked improvement in crises during the holidays; it would diminish the intellectual performances. In addition, migraine was more common among students in vocational education than in general education [38]. In 1992, Stewart et al. [41] had the opposite hypothesis, namely that migraine sufferers, embarrassed by their illness, would be less well educated and therefore have access to lower-paying occupations than nonmigraine sufferers.

The family history of headache was found in $60.9 \%$ of our migraine patients with a significant difference compared to 
the rest of the study population. In 1996, Russell et al [42] established that having a first-degree relative with migraine increases the risk of migraine. The risk of migraine without aura is multiplied by 1.9 for first-degree, relatives that, of migraine with aura are multiplied by four. We found in our study results in agreement with the data of the literature; a family history of migraine in $65.3 \%$ of subjects with migraine with aura and $57.6 \%$ in migraine without aura. Pelzer et al [43] reported that migraine attacks are much more common in patients with a history of migraine in parents. It is in this same perspective that McGregor [44] states that subjects with a migraine parent have a $40 \%$ risk of being migraine and when both parents are, the risk is $75 \%$.

\section{Conclusion}

The prevalence of migraine is high in Brazzaville, it differs according to the districts, from 5.5 to $24.6 \%$, according to the existence or not of the favorable factors. Migraine affects the young adult and more preferably the woman with a sex ratio of 0.57 . A family history of migraine is found in the majority of cases. The migraine without aura remains the most frequent form. The knowledge of the epidemiology of migraine in Brazzaville will lead to better awareness-raising actions to reduce the ignorance of this condition, which is most often a source of self-medication and sources of increased expenditure related to health.

\section{References}

[1] Headache Classification Committee of the International Headache Society (IHS). The International Classification of Headache Disorders, 3rd edition (beta version). Cephalalgia 2013; 33 (9): 629-808.

[2] Dodick DW, Migraine. http: www.thelancet.com Published online March 6, 2018 http: //dx.doi.org/10.1016/S01406736(18)30478-1.

[3] World Health Organization. Headache disorders, FactsheetN277.2016. http: //www.who.int/mediacentre/factsheets/fs277/en/. consultésept 2018.

[4] Ahmed MAK, Haddad M, Kouassi B, Ouhabi H, Serrie A. Consensus formalisé: recommandations de pratiques cliniques pour la prise en charge de la migraine du patient adulte africain. Pan AfricanMedical Journal. 2016; 24: 81.

[5] Lanteri-Minet M, Valade D, Geraud G, Lucas C, Donnet A. Prise en charge diagnostique et thérapeutique de la migraine chez l'adulte et l'enfant: aspects cliniques et économiques 2002. Revue Neurologique. 2013; 169: 14-29.

[6] Headache Classification Committee of the International Headache Society (IHS). The International Classification of Headache Disorders, 3rd edition. Cephalalgia 2018; 38 (1): 1211.

[7] Marcelo E, Bigal ME, Richard B. Lipton RB. The Epidemiology, Burden, and Comorbidities of Migraine. Neurology clinic 2009; 27 (2): 321-34.
[8] Woldeamanuel YW, Robert P. Cowan Migraine affect 1 in 10 people worldwide featuring recent rise: A systematic review and meta-analysis of community-based studies involving 6 million participants. Journal Neurological Science. 2016; 372: 307-15..

[9] Ossou-Nguiet PM, Gnonlonfoun D, Matali E, Obondzo-Aloba $\mathrm{K}$, Nguienia D, Banzouzi L, et al. Drug overuse and chronic headaches in Brazzaville: Patients profile and therapeutic itinerary. Cephalalgia. 2015; 35 (6s): 106.

[10] Kube Technologie2017.commune de Brazzaville, Congo: les arrondissements. «http:www.brazzaville.cg/fr». consulté en novembre 2017

[11] Atlas des populations et pays du monde en 2017. http:www.populationdata.net/pays/congo. Consulté en janvier 2018

[12] Vos T, Flaxman AD, Naghavi M, Lozano R, Michaud C, Ezzati $\mathrm{M}$ et al. Years lived with disability (YLDs) for 1160 sequelae of 289 diseases and injuries 1990-2010: A systematic analysis for the Global Burden of Disease Study 2010. Lancet 2012;380:2163-96.

[13] GBD Headache Collaborators. Global, regional, and national burden of migraine and tension-type headache, 1990-2016: a systematic analysis for the Global Burden of Disease Study 2016. Lancet Neurology. 2018; 17: 954-76.

[14] El-Sherbiny NA, Masoud M, Shalaby NM, Shehata HS. Prevalence of primary headache disorders in Fayoum Governorate, Egypt. Journal of Headache Pain. 2015; 16: 85.

[15] Mbewe E, Zairemthiama P, Yeh H-H, Paul R, Birbeck GL, Steiner TJ. The epidemiology of primary headache disorders in Zambia: a population-based door-to-door survey. Journal of Headache and Pain. 2015; 16: 30.

[16] Gururaj G, Kulkarni GB, Rao GN, Subbakrishna DK, Stovner LJ, Steiner TJ. Prevalence and Sociodemographic Correlates of Primary Headache Disorders: Results of a Population-based Survey from Bangalore, India. Indian Journal of Public Health. 2014; 58 (4): 241-8.

[17] Zebenigus M, Tekle-Haimanot R, Worku DK, Thomas H, Steiner TJ. The prevalence of primary headache disorders in Ethiopia. Journal of Headache and Pain. 2016; 17: 110.

[18] Adoukonou TA, Houinato DS, Adjien KC, Gnonlonfoun D, Avode DG, Preux P-M. Prévalence de la migraine dans une population de travailleurs à Cotonou au Bénin. African Journal of Neurological Sciences. 2009; 28 (1): 16-22.

[19] Maiga Y, Soumaila B, Drissa K, Yacouba C, Sara D, Lala C et al. La migraine en milieu scolaire à Gao au Mali. African Journal of Neurological Sciences. 2011; 30 (2): 49-55.

[20] Adoukonou T, Tognon-Tchegnonsi T, Kouna P, Alabi A, Houinato D, Preux PM. Prevalence of migraine among university students at Parakou, Benin: A cross-sectional study. World Journal of Neurosciences. 2014; 4: 18-24.

[21] Manandhar K, Risal A, Steiner TJ, Holen A, Linde M. The prevalence of primary headache disorders in Nepal: a nationwide population-based study. Journal of Headache Pain. 2015; 16: 95.

[22] Phanthumchinda K, Sithi-Amorn C. Prevalence and clinical features of migraine: a community survey in Bangkok, Thailande. Headache: Journal of Head and Face Pain. 1999; 29 (9): 594-97. 
[23] Henry P, Auray JP, Gaudin AF, Dartigues JF, Duru G, LantériMinet M, Lucas $\mathrm{C}$, et al. Prevalence and clinicalcharacteristics of migraine in France. Neurology. 2002; 59: 232-7.

[24] Ayzenberg I, Katsarava Z, Sborowski A, Chernysh M, Osipova V, Tabeeva G, Steiner TJ. Headache-attributed burden and its impact on productivity and quality of life in Russia: structured healthcare for headache is urgently needed. European Journal of Neurology. 2014; 21: 758-65.

[25] Streel S, Donneau AF, Hoge A, Albert A, Schoenen J, Guillaume M. One-year prevalence of migraine using a validated extended French version of the ID MigraineTM: A Belgian population-based study. Review of Neurology. 2015; 171: 707-14.

[26] Katsarava K, Dzagnidze A, Kukava M, Mirvelashvili E, Djibuti M, Janelidze M et al.Primary headache disorders in the Republic of Georgia: Prevalence and risk factors. Neurology. 2009; 73: 1796-803.

[27] Stovner LJ, Al Jumah M, Birbeck GL, Gururaj G, Jensen R, Katsavara $\mathrm{Z}$ et al. The methodology of population survey of headache prevalence, burden and cost: Principles and recommandations from the Global Campaign against Headache. Journal of Headache Pain. 2014; 15: 5.

[28] Özdemir G, Aygül R, Demir R, Özel L, Ertekin A, Ulvï H. Migraine prevalence, disability, and sociodemographic properties in the eastern region of Turkey: a population-based door-to-door survey. Turk Journal of Medical Sciences. 2014; 44: 624-9.

[29] Charles A. The Migraine Aura. Continuum: Lifelong learning in Neurology. 2018; 24 (4): 1009-22.

[30] Solotareff L, Cuvellier JC, Duhamel A, Vallée L, Tich SNT. Trigger factors in childhood migraine: A prospective clinicBased Study from north of France. Journal of Child Neurology. 2017; 32 (8): 754-8.

[31] Schroeder RA. Brandes J, Buse DC, Calhoun A, EikermannHaeter K, Golden K. Sex and gender differences in migraineEvaluating knowledge gaps. Journal of Women's Health. 2018; 27 (8): 965-73.

[32] Chai NC, Peterlin BL, Calhoun AH. Migraine and oetrogen. Current Opinion Neurology. 2014; 27 (3): 315.

[33] Cappy H, Lucas C, Catteau-Jonard S, Robin G. Migraine and contraception. Gynécologie Obstétrique \& Fertilité. 2015; 43: 234-41.
[34] Antonaci F, Voiticovschi-Iosob C, Di Stefano AL, Galli F, Ozge A, Balottin U. The evolution of headache from childhood to adulthood: A review of literature. Journal of Headache Pain. 2014; 15: 15

[35] Burch R, Rizzoli P, Loder E. The Prevalence and Impact of Migraine and Severe Headache in the United States: Figures and Trends From Government Health Studies. Headache. 2018; 58: 496-505.

[36] Schroeder RA, Brandes J, Buse DC, Calhoun A, EikermannHaerter K, Golden K et al. Sex and Gender Differences in Migraine-Evaluating Knowledge Gaps. Journal of Women's Health. 2018; 27 (8): 965-73.

[37] Victor T, Hu X, Campbell J, Buse D, Lipton R. Migraine prevalence by age and sex in United States: A life-span study. Cephalalgia. 2010; 30: 1065-72.

[38] Maiga Y, Soumaïla B, Cissoko L N, Sangaré M, Diallo SH, Diallo S, et al. Epidemiology of migraine among students in Mali. Ensci. 2017, doi:10.1016/j.ensci.2017.04.001.

[39] Adoukonou T, Houinato D, Kankouan J, Makoutode M, Paraiso M, Tehindrazanarivelo A. et al. Migraine Among University Students in Cotonou (Benin). Headache. 2009; 49: 887-93.

[40] Henry P. Comprendre et combattre la migraine, 2e édition Flammarion, Paris, 2003.

[41] Stewart WF, Lipton RB, Celentano DD, Reed ML. Prevalence of Migraine Headache in the United States. Relation to Age, Income, Race, and Other Sociodemographic Factors. JAMA. 1992; 267: 64-9.

[42] Russell MB, Iselius L, Olesen J. Migraine without aura an Migraine with aura are herited disorders. Cephalalgia. 1996;16(5):305-9.

[43] Pelzer N, Louter MA, van Zwet EW, Nyholt DR, Ferrari MD, van den Maagdenberg AMJM et al. Linking migraine frequency with family story of migraine. Cephalalgia. 2018; 0 (0): $1-8$

[44] MacGregor EA. Migraine clinic. American College of Physicians. Annals of Internal Medicine. 2017:50-64. doi: 10.7326/AITC201704040. 